\title{
More money, more problems? Can high pay be coercive and repugnant?
}

Ambühl, Sandro ; Niederle, Muriel ; Roth, Alvin E

\begin{abstract}
IRBs can disallow high incentives they deem coercive. A vignette study on MTurk concerning participation in medical trials shows that a substantial minority of subjects concurs. They think high incentives cause more regret, and that more people would be better off without the opportunity to participate. We model observers as judging the ethicality of incentives by partially using their own utility. The model predicts that payments are repugnant only to the extent that they affect the participation decision, and more so for larger transactions. Incentivizing poorer participants is more repugnant, and in-kind incentives are less repugnant than monetary incentives.
\end{abstract}

DOI: https://doi.org/10.1257/aer.p20151034

Posted at the Zurich Open Repository and Archive, University of Zurich ZORA URL: https://doi.org/10.5167/uzh-182661

Journal Article

Published Version

Originally published at:

Ambühl, Sandro; Niederle, Muriel; Roth, Alvin E (2015). More money, more problems? Can high pay be coercive and repugnant? American Economic Review, 105(5):357-360.

DOI: https://doi.org/10.1257/aer.p20151034 


\title{
More Money, More Problems? Can High Pay be Coercive and Repugnant?
}

\author{
By Sandro Ambuehl, Muriel Niederle, and Alvin E. Roth*
}

Sometimes two people would voluntarily agree to transact a good or service for compensation, but an unaffected third party would prefer to prevent this transaction. Paid kidney donation, prostitution, and paid participation in medical trials are examples. We use a vignette study to explore how respondents' assessments of such repugnant transactions change as we alter the seller's compensation. ${ }^{1}$ We then sketch a model of how people judge the ethics of such transactions. $^{2}$

We focus on transactions involving two parties, for which there are no material negative externalities. ${ }^{3}$ By considering a single transaction we abstract from general equilibrium effects (cf. Basu 2007). We focus on the seller of the good and not the buyer.

*Ambuehl: Stanford University, 597 Serra Mall, Stanford, CA 94305 (e-mail: sambuehl@stanford.edu); Niederle: Stanford University, 597 Serra Mall, Stanford, CA 94305 (e-mail: niederle@ stanford.edu); Roth: Stanford University, 597 Serra Mall, Stanford, CA 94305 (e-mail: alroth@stanford.edu).We thank Debra Satz and participants at the Stanford Behavioral and Experimental Lunch and the ASSA annual meeting 2015 for helpful comments and discussions.

${ }^{\dagger}$ Go to http://dx.doi.org/10.1257/aer.p20151034 to visit the article page for additional materials and author disclosure statement(s).

${ }^{1}$ We defer the harder question of why transacting one good or service is widely viewed as repugnant whereas a closely related transaction is not (e.g., surrogate motherhood and external childcare).

${ }^{2}$ Repugnant transactions have been studied in the moral philosophy literature. Examples include Satz (2010) and Sandel (2012). Roth (2007) views repugnant transactions from a market design perspective. Due to the dearth of empirical data, we ran the survey before developing the model.

${ }^{3} \mathrm{~A}$ transaction exerts no material externalities on a third party $C$ if $C$ cannot infer whether or not it occurred, unless an external source informs him about it. In particular, given $C$ 's ex ante beliefs about the likelihood of the transaction, $C$ 's utility is unaffected by its occurrence unless he learns about it through an external source.

\section{Survey}

Our survey concerns paid participation in medical experiments. The extant regulatory literature cautions against substantial monetary compensation for participation, particularly for the socioeconomically disadvantaged. According to the National Bioethics Advisory Commission (2001), "benefits threaten ... the voluntary nature of the choice, ... raise ... the danger that the potential participant's distributional disadvantage could be exploited $[$ and $]$... lead some prospective participants to enroll ... when it might be against their better judgment and when otherwise they would not do so." The medical ethics guidelines of jurisdictions as diverse as the European Union, India, and Kenya contain such language.

For economists, these arguments are hard to understand. According to revealed preference theory, enlarging an agent's choice set can only make him better off. Hence preventing transactions that have no negative material externalities cannot improve welfare.

We wish to understand whether there is a widespread perception in the population that high payments for participation in clinical trials are indeed ethically inappropriate, and if so, why?

We presented 1,445 subjects on Amazon Mechanical Turk with a fictitious medical trial that compensates participants with $\$ 50, \$ 1,000$, or $\$ 10,000$. We described it as a test for side effects of a vaccine that requires a total of 40 hours of a participant's time, and characterized it as low but nonzero risk. Each respondent was randomly displayed one of the three payment amounts and answered several questions, including how they would decide as a member of the IRB responsible for approving the experiment, before answering the same questions for each of the remaining amounts. The last page of the survey directly juxtaposed the three payment 
amounts, as well as the policies of paying $\$ 0$ and covering participants' opportunity costs. ${ }^{4}$ Respondents rated the ethical appropriateness of each of these. ${ }^{5}$

Since respondents might not independently think of pertinent ethical aspects, we added an experimental condition for 55 percent of our respondents presenting the following argument, inspired by Satz (2010), and framed as a discussion between the designers of the study: "Does ... payment ... draw people into the study ... who do not entirely understand what they are getting into? ... [Is the] decision to participate ... truly voluntary when a substantial payment is offered?" 6

\section{A. Results}

We use respondents' ratings of how ethical is each payment to categorize them as one of three types. "Economists" rate a payment of $\$ 10,000$ strictly more ethical than a payment of $\$ 1,000$. "Ethicists" make the opposite assessment. The remaining subjects rate both equally. ${ }^{7}$ When (no) arguments were provided, (57 percent and 14 percent) 34 percent and 27 percent of respondents were "economists" and "ethicists," respectively. We now show that "ethicists" on the IRB would reject the experiment more when the highest payment was offered, and feel that high payments damage decision making.

Figure 1 plots respondents' reactions to varying payment amounts separately for "economists" and "ethicists." We use only the first stage of the survey, and hence each respondent appears only for one payment amount. We pool data over the two treatments. ${ }^{8}$

\footnotetext{
${ }^{4}$ Israel reimburses living organ donors with an amount of money equal to 40 days of the donor's average income during the three months prior to donation.

${ }^{5}$ We use only the ordinal information contained in these ratings.

${ }^{6}$ In the direct juxtaposition, these respondents additionally read: “... the Institute might entice women to participate in the study who don't fully understand what they are getting into. ... might lead people to participate in the study who would not otherwise choose to do so." The full text of the survey is in the online Appendix.

${ }^{7}$ Subjects saw both payment amounts which referred to the same hypothetical medical trial. Hence differential responses cannot be caused by differential inference about the riskiness of the trial.

${ }^{8}$ The results are directionally the same on either subsample (see the online Appendix).
}

Panel A. Economists

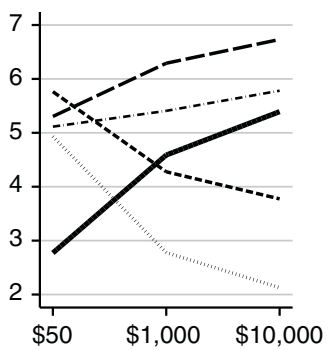

Panel B. Ethicists

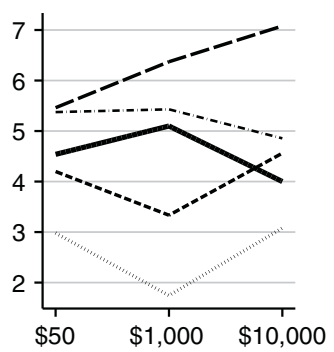

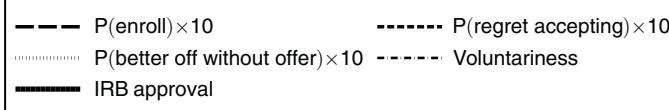

Figure 1. Responses of "Economists" and "Ethicists"

Both types believe higher payments are more effective incentives $(p<0.1)$, and agree on the sign of the comparative statics of raising payment from $\$ 50$ to $\$ 1,000$ on all questions. 9 They differ in assessing the effects of raising incentives to $\$ 10,000$. "Ethicists" think very high incentives make participants who enroll more likely to subsequently regret their decision $(p<0.01)$, consistent with the hypothesis that very high incentives may lead to worse decision making. They think more prospective participants would be better off if they had never seen the offer to participate in this case $(p<0.01)$. They also consider the decision to accept less voluntary $(p=0.01)$ when very high incentives are offered. The opposite comparative statics apply to "economists" ( $p<0.05$ in all cases). Consistent with this, "ethicists" ("economists") state that as a member of the IRB they would approve the study less (more) if the incentive is $\$ 10,000$ rather than $\$ 1,000(p<0.01$ for both types). ${ }^{10}$

\footnotetext{
${ }^{9}$ A majority of both "economist" and "ethicist" types consider some form of payment more ethical than purely voluntary participation (94 percent and 66 percent, respectively); disagreement mainly concerns the appropriate amount.

${ }^{10}$ This variable is different from the one used to define the types, and hence shows the individual consistency of the types. In within rather than across subjects data, both types think that very high payments decrease the voluntariness of the choice (but "ethicists" much more so than "economists") and the likelihood of regret after having enrolled into the trial (but "ethicists" much less so than "economists").
} 
Respondents' own characteristics are predictive of their type. In a joint regression, higher income, education, and age all increase the likelihood a respondent is an "ethicist" $(p<0.1$, 0.05 , and 0.05 , respectively). The 56 percent of respondents who have "thought about participating in a medical research study as a means to earn money" are more likely "ethicists" than our other subjects $(p<0.05){ }^{11}$

\section{Sketch of a Model}

A prospective seller $s$ is offered $\bar{m}$ units of money in exchange for an amount $\bar{x}$ of a good such as health, and can freely decide to accept or reject. An observer $o$ who is richer than any seller judges the ethicality of the offer by judging the expected welfare of a participant. Agent $i$ 's endowment is $\left(h, m_{i}\right)$ and his utility from $h$ units of health and $m$ units of money is $U_{i}\left(h, m_{i}\right)=a_{i} u(h)+v\left(m_{i}\right)$ with $v^{\prime}(\cdot)>0$ and $v^{\prime \prime}(\cdot)<0, i \in\{s, o\}$. There is heterogeneity in both $a_{i}$ and $m_{i}$. The distribution of sellers who participate is the population distribution conditional on being willing to participate.

While the observer is able to correctly predict the seller's behavior, he does not assume that choice is utility maximizing. Instead, he partially takes the seller's perspective, and asks how he would feel if he had to live with the seller's choice. Hence the observer is (partially) paternalistic in his assessment of the welfare of the seller. Formally, he judges welfare from the point of view of someone with monetary endowment $m_{\rho}=\rho m_{s}+(1-\rho) m_{o}$, where $\rho \in(0,1) .{ }^{12}$ Assessed welfare is $w(\bar{h}, \bar{m})$ $=a_{s} u(h-\bar{h})+v\left(m_{\rho}+\bar{m}\right)$. The ethicality of the transaction is $e(\bar{h}, \bar{m})=E[w(\bar{h}, \bar{m})-$ $\left.w(0,0) \mid U_{s}\left(h-\bar{h}, m_{s}+\bar{m}\right) \geq U_{s}\left(h, m_{s}\right)\right]$. The transaction is considered repugnant if $e<0 .{ }^{13}$

\footnotetext{
${ }^{11}$ Fourteen percent of those subjects report having participated in a clinical trial. This has no additional effect on the likelihood of being an "ethicist."

${ }^{12}$ In the online Appendix we study the case in which the observer also only partially takes the seller's perspective regarding the preference parameter $a$.

${ }^{13}$ Offering a transaction to a prospective seller can be unethical only if the observer judges the seller according to a standard different from the one he uses to predict his behavior. Plainly, partial perspective taking implies that the observer would never participate in a transaction that he finds repugnant, but may refuse to participate in a transaction that he does not find repugnant.
}

\section{A. Implications}

We first study the effects of incentivizing a given seller, and then consider selection. Suppose the seller is offered a transaction he is just willing to accept. As the observer assesses welfare from the point of view of someone with a lower marginal utility of money, he thinks that the seller loses from accepting this transaction. Hence, he judges offering this transaction to the seller as repugnant. This shows that money is considered repugnant to the extent that it incentivizes the transaction, not per se. Indeed, paying the seller more for providing the same amount $\bar{h}$ is judged as more ethical. Both results are in line with the ethics literature cited above.

Incentivizing the sale of a larger amount $\bar{h}$ is judged as less ethical. ${ }^{14}$ The observer thinks that the seller loses from a transaction that makes him indifferent. The larger the payment needed to make him indifferent, the more he loses. This comparative static is stronger for richer observers.

Incentivizing poorer sellers is judged as less ethical (if $v$ has non-increasing absolute risk-aversion) since the observer disagrees with poorer sellers more about the marginal value of money. This explains why medical ethics guidelines are particularly concerned about incentivizing socioeconomically disadvantaged populations. And $e$ is decreasing in the observer's endowment because richer observers take the seller's perspective to a lesser extent when assessing welfare.

Regarding market design, the model implies that in-kind incentives will be judged as most ethical. ${ }^{15}$ Once there is no trade-off between good $h$ and money, there is no scope for disagreement about the appropriate rate of substitution. The model also explains why 73 percent of our survey respondents consider remunerating subjects with the opportunity costs as worse than (at least one of) paying $\$ 1,000$ or $\$ 10,000 .^{16}$

\footnotetext{
${ }^{14}$ Formally, increasing $\bar{h}$ and varying $\bar{m}$ such that the seller's utility from accepting the transaction is unchanged decreases $e$. All proofs are in the online Appendix.

${ }^{15}$ In-kind compensation occurs, for example, in kidney exchange. A richer model would introduce room for disagreement by allowing the observer's preferences for good $h$ to differ from the seller's.

1687 percent and 69 percent amongst "economist" and "ethicist" subjects, respectively.
} 
Starting from two prospective sellers with different endowments $m_{1}<m_{2}$ who are given the respective least amount of money $\bar{m}_{1}<\bar{m}_{2}$ that just makes them participate, $\bar{m}_{1}$ can be increased to $\bar{m}_{2}$ without affecting any participation decisions. Since high payments are viewed as unethical only to the extent they serve as incentives, this raises $e$.

When allowing for selection, increasing incentives for selling a given amount $\bar{h}$ has three effects: (i) sellers who would have participated anyway now receive a larger consumer surplus; (ii) richer sellers, who would not have participated before, now do; (iii) sellers with higher utility weight $a_{s}$ on good $h$ now participate. The first two effects increase $e$. The third is akin to incentivizing a larger transaction and decreases $e$. The total effect depends on the population distribution of $a_{s}$ and $m_{s}$, and can take the hump shape observed for "ethicist" survey respondents.

A promising direction for further empirical research may be to study the attitudes of subjects drawn from the same population as potential participants in a study. An IRB might wish to know if people with the same income as the participants of concern feel that high incentives are repugnant.

\section{REFERENCES}

Basu, Kaushik. 2007. "Coercion, contract and the limits of the market." Social Choice and Welfare 29 (4): 559-79.

National Bioethics Advisory Commission (NBAC). 2001. Ethical and Policy Issues in Research Involving Human Participants. Bethesda, MD: NBAC

Roth, Alvin E. 2007. "Repugnance as a Constraint on Markets." Journal of Economic Perspectives 21 (3): 37-58.

Sandel, Michael J. 2012. What Money Can't Buy: The Moral Limits of Markets. New York: Farrar, Straus and Giroux.

Satz, Debra. 2010. Why Some Things Should Not Be For Sale: The Moral Limits of Markets. Oxford: Oxford University Press. 


\section{This article has been cited by:}

1. Julio J. Elías, Nicola Lacetera, Mario Macis. 2019. Paying for Kidneys? A Randomized Survey and Choice Experiment. American Economic Review 109:8, 2855-2888. [Abstract] [View PDF article] [PDF with links]

2. Chen Lian, Yueran Ma, Carmen Wang. 2019. Low Interest Rates and Risk-Taking: Evidence from Individual Investment Decisions. The Review of Financial Studies 32:6, 2107-2148. [Crossref]

3. Martin Hagen. 2019. Refugee Relocation: A Mechanism Design Perspective. SSRN Electronic Journal . [Crossref]

4. Aviva M. Goldberg, Amy Bobrowski, Aaron Wightman. 2019. Crowdsourcing in pediatric transplant studies-An opportunity for reflection on research ethics. Pediatric Transplantation 23:8. . [Crossref]

5. Dorothea Kübler, Julia Schmid, Robert Stüber. 2018. Gender discrimination in hiring across occupations: a nationally-representative vignette study. Labour Economics 55, 215-229. [Crossref]

6. Philip J. Held, Frank McCormick, Glenn M. Chertow, Thomas G. Peters, John P. Roberts. 2018. Would government compensation of living kidney donors exploit the poor? An empirical analysis. PLOS ONE 13:11, e0205655. [Crossref]

7. Alvin E. Roth. 2018. Marketplaces, Markets, and Market Design. American Economic Review 108:7, 1609-1658. [Abstract] [View PDF article] [PDF with links]

8. Michael A. Clemens. 2018. Testing for Repugnance in Economic Transactions: Evidence from Guest Work in the Gulf. The Journal of Legal Studies 47:S1, S5-S44. [Crossref]

9. Sandro Ambuehl, Axel Ockenfels, Colin Stewart. 2018. For They Know Not What They Do: Selection Through Incentives When Information is Costly. SSRN Electronic Journal . [Crossref]

10. Shengwu Li. 2017. Ethics and market design. Oxford Review of Economic Policy 33:4, 705-720. [Crossref]

11. Sandro Ambuehl, Axel Ockenfels. 2017. The Ethics of Incentivizing the Uninformed: A Vignette Study. American Economic Review 107:5, 91-95. [Abstract] [View PDF article] [PDF with links]

12. M. A. Rees, T. B. Dunn, C. S. Kuhr, C. L. Marsh, J. Rogers, S. E. Rees, A. Cicero, L. J. Reece, A. E. Roth, O. Ekwenna, D. E. Fumo, K. D. Krawiec, J. E. Kopke, S. Jain, M. Tan, S. R. Paloyo. 2017. Kidney Exchange to Overcome Financial Barriers to Kidney Transplantation. American Journal of Transplantation 17:3, 782-790. [Crossref]

13. Nicola Lacetera. 2017. Incentives and Ethics in the Economics of Body Parts. SSRN Electronic Journal . [Crossref]

14. Shengwu Li. 2017. Ethics and Market Design. SSRN Electronic Journal . [Crossref]

15. Michael A. Clemens. 2017. Testing for Repugnance in Economic Transactions: Evidence from Guest Work in the Gulf. SSRN Electronic Journal . [Crossref]

16. Sandro Ambuehl. 2016. An Offer You Can't Refuse? Incentives Change What We Believe. SSRN Electronic Journal . [Crossref]

17. Sandro Ambuehl, Axel Ockenfels. 2016. The Ethics of Incentivizing the Uninformed. A Vignette Study. SSRN Electronic Journal . [Crossref] 